\title{
Dimensions and dynamics in integrin function
}

K.M. Yamada ${ }^{1}$,

R. Pankov ${ }^{1}$ and

E. Cukierman ${ }^{1,2}$

\author{
${ }^{1}$ Craniofacial Developmental Biology and Regeneration Branch, \\ National Institute of Dental and Craniofacial Research, \\ National Institutes of Health, Bethesda, MD, USA \\ ${ }^{2}$ Basic Science Division, Fox Chase Cancer Center, Philadelphia, PA, USA
}

\section{Correspondence}

K.M. Yamada

CDBRB, NIDCR, NIH

Building 30, Room 421

30 Convent Drive MSC 4370

Bethesda, MD 20892-4370

USA

Fax: +1-301-402-0897

E-mail: kenneth.yamada@nih.gov

Presented at SIMEC 2002

(International Symposium

on Extracellular Matrix),

Angra dos Reis, RJ, Brazil,

October 7-10, 2002

Received February 27, 2003

Accepted April 15, 2003

\begin{abstract}
Integrins play crucial roles in cell adhesion, migration, and signaling by providing transmembrane links between the extracellular matrix and the cytoskeleton. Integrins cluster in macromolecular complexes to generate cell-matrix adhesions such as focal adhesions. In this minireview, we compare certain integrin-based biological responses and signaling during cell interactions with standard 2D cell culture versus 3D matrices. Besides responding to the composition of the matrix, cells sense and react to physical properties that include three-dimensionality and rigidity. In routine cell culture, fibroblasts and mesenchymal cells appear to use focal adhesions as anchors. They then use intracellular actomyosin contractility and dynamic, directional integrin movements to stretch cell-surface fibronectin and to generate characteristic long fibrils of fibronectin in "fibrillar adhesions". Some cells in culture proceed to produce dense, three-dimensional matrices similar to in vivo matrix, as opposed to the flat, rigid, two-dimensional surfaces habitually used for cell culture. Cells within such more natural 3D matrices form a distinctive class of adhesion termed "3Dmatrix adhesions". These 3D adhesions show distinctive morphology and molecular composition. Their formation is heavily dependent on interactions between integrin $\alpha_{5} \beta_{1}$ and fibronectin. Cells adhere much more rapidly to 3D matrices. They also show more rapid morphological changes, migration, and proliferation compared to most 2D matrices or 3D collagen gels. Particularly notable are low levels of tyrosine phosphorylation of focal adhesion kinase and moderate increases in activated mitogen-activated protein kinase. These findings underscore the importance of the dimensionality and dynamics of matrix substrates in cellular responses to the extracellular matrix.
\end{abstract}

\section{Introduction}

Integrins are the major vertebrate receptors for extracellular matrix molecules. Besides mediating cell adhesion and migration, they help to regulate critical cellular signaling processes that range from cell growth
Key words

- Extracellular matrix

- Cell adhesion

- Integrin

- Fibronectin

- Signal transduction

- Migration and apoptosis to specific gene regulation. The field of integrin biology has grown explosively over the past decade, and it now encompasses broad areas of cell biology, structural biology, and medicine that have been the subject of a variety of recent reviews (1-13). In this brief mini-review we 
will focus on roles of integrins in the formation of a fibrillar extracellular matrix and then on the cellular responses to extracellular matrix from our personal perspective. We will review studies showing that, besides its biochemical composition, important features of the extracellular matrix that govern the cellular responses it elicits include its threedimensionality and its deformability or rigidity. In-depth reviews of other aspects of integrin-based cell-matrix interactions with many more citations than possible in this mini-review have been published previously (1-10,14-19).

\section{Formation of extracellular matrices - the importance of dynamics}

Although the capacity of purified collagen to self-assemble into fibrils in the absence of cells has been a central conceptual paradigm of matrix biochemistry, the way in which collagen molecules produced by living cells actually become organized into extracellular fibrillar matrices in vivo appears to be under cellular control. In fact, both older and very recent studies provide strong evidence that the fibrillar organization of collagens type I and III, at least in the early stages of organization, depends on the preceding organization of another matrix protein - fibronectin (20-22). Since other extracellular molecules also often co-localize with fibronectin fibrils, it is obviously important to understand how cells form fibrils of fibronectin. Much is now known about the biochemistry of fibronectin matrix assembly $(7,23)$. Crucial elements identified to date include the binding of soluble fibronectin molecules by integrins and then exposure of cryptic fibronectin self-assembly sites to promote self-association; the mechanism for exposure of specific cryptic sites is thought to involve tension $(24,25)$, i.e., stretching of fibronectin by intracellular contractility $(7,23$, 26-29).

Integrin and fibronectin dynamics on the cell surface can be tracked by using nonperturbing antibody tracers and directly labeled fibronectin (30). Different patterns of integrin behavior were identified for two types of integrin receptors. The multi-ligand receptor $\alpha_{V} \beta_{3}$ remains within focal adhesions. In contrast, the fibronectin receptor $\alpha_{5} \beta_{1}$ translocates out of focal contacts at 6.5 $\mu \mathrm{m} / \mathrm{h}$ along fibrillar adhesions (previously termed "extracellular matrix contacts") in parallel to actin microfilament bundles (30). Fibronectin is translocated in a very similar pattern $(28,30)$. Tensin is a primary cytoskeletal component of fibrillar adhesions, and it also moves in a parallel fashion (31). In fact, a dominant-negative inhibitor of tensin blocks integrin translocation, fibrillar adhesion formation, and fibronectin fibrillogenesis without affecting focal adhesions (30). As shown diagrammatically in Figure 1 , we proposed that translocating $\alpha_{5} \beta_{1}$ integrins induce initial fibronectin fibrillogenesis by transmitting cytoskeleton-generated tension to extracellular fibronectin molecules. In fact, blocking this integrin translocation by a variety of treatments prevents both the formation of fibrillar adhesions and fibronectin fibrillogenesis. Thus, fibronectin fibrils appear to be generated by a process of localized, directional, integrin translocation, which exposes cryptic domains on the fibronectin molecule, allowing polymerization into fibers and resulting in matrix assembly.

\section{Cellular responses to extracellular matrices - the importance of dimensions}

Once the extracellular matrix is formed, it can regulate numerous aspects of cell behavior (32). A variety of studies of cells cultured in three-dimensional collagen gels and reconstituted basement membrane matrix have underscored the importance of considering cells in more physiological microenvironments than growth on flat tissue culture substrates (32-39). For example, fibroblasts 
in collagen gels under different degrees of tension behave quite differently (40-43), and epithelial cells in three-dimensional environments show major differences in biosynthesis of differentiated products (44) or in responses to apoptotic stimuli $(45,46)$.

Although a variety of systems have been developed to mimic physiological three-dimensional environments (36,37), a recent approach involves using tissue- or cell culture-derived three-dimensional matrices for analyzing the behavior of migratory and mesenchymal cells $(47,48)$. The logic behind this approach is that cells do not normally encounter a pure collagen matrix, nor a multimillimeter-thick basement membrane. Instead, they exist in complex environments comprised of multiple molecules and a substantial degree of fibrillar organization with complexity beyond that provided by collagen gels. Recent findings indicate that cells respond differently to such complex 3D matrices compared to collagen gels or flat tissue culture substrates.

Cryostat sections of tissues of embryos from which cellular contents have been extracted with alkaline detergent solution provide a well-organized fibrillar extracellular matrix that can be used as a system for culturing fibroblastic cells in three dimensions. It can be mimicked effectively by ex- tracting morphologically similar dense extracellular matrices accumulated by certain cultured fibroblasts after multiple days of cell culture. In both cases, a key component of these matrices is fibronectin, along with collagen I and heparan sulfate proteoglycan (Cukierman E, unpublished results). Cells plated into such matrices show greater than 6-fold rates of cell attachment compared to purified collagen gels, as well as compared to substrates of purified fibronectin, laminin, or collagen I (47). As initially established for fibroblasts and other cells plated in collagen gels $(32,33,49)$, they acquire an in vivo-like fibroblastic shape that is slender and elongated, rather than flattened and triangular (Figure 2). However, the rate at which human fibroblasts acquire such morphology is much faster in the natural 3D matrices compared to collagen gels; the final morphology is also slightly different. Interestingly, even rates of cell proliferation appear to be augmented more than 2-fold above proliferation rates on the excellent cell culture substrate fibronectin. Finally, cell migration is augmented on such matrices compared to fibronectin, collagen, or 3D collagen gels (47).

Are the effects of complex matrices due to the individual molecular components or to the overall 3D organization? The answer seems to

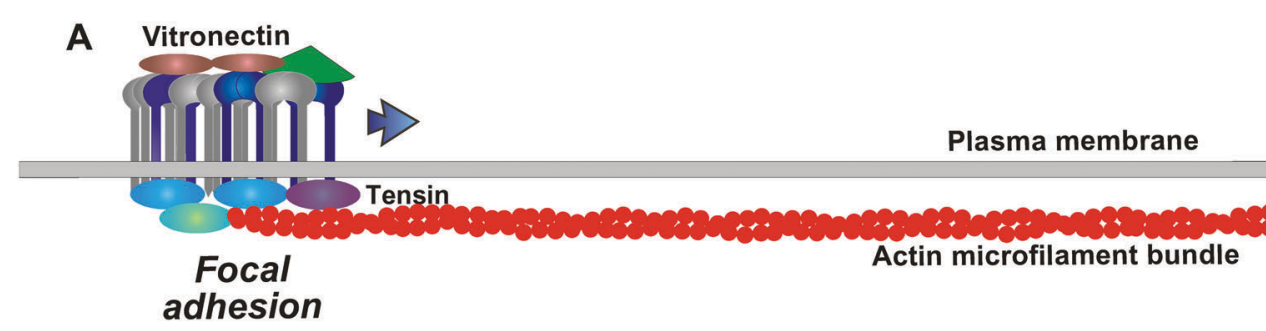

B

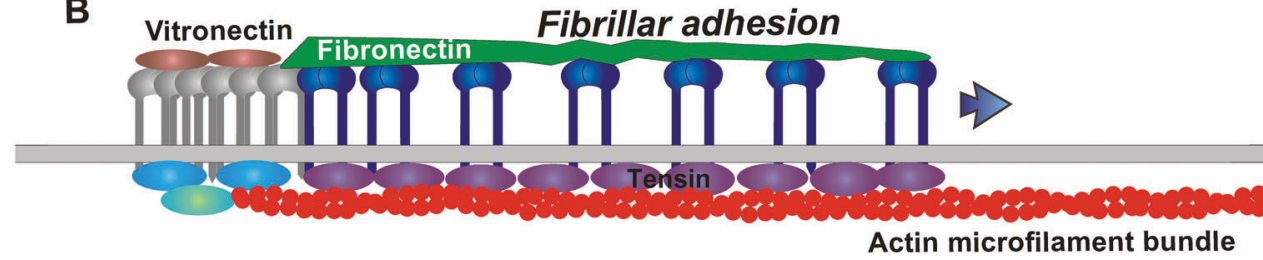

Figure 1. Integrin translocation mechanism for fibronectin matrix assembly. Cells use focal adhesions as anchors, e.g., for mediating strong adhesion to vitronectin using the $\alpha v \beta_{3}$ integrin (A). Intracellular contractility and dynamic, directional movement of the $\alpha_{5} \beta_{1}$ integrin (blue) along actin microfilament bundles from the cell periphery towards the cell center results in a pulling and stretching of fibronectin. The tension from stretching is thought to cause local unfolding of the fibronectin molecule, which exposes cryptic binding sites for assembling a linear fibronectin fibril (B). This process requires the cytoskeletal protein tensin and intracellular actomyosin contractility. 
be a combination: flattening the 3D matrices by mechanical force (using a Teflon-covered lead weight) or by coating culture substrates with all of the same molecules using a mixture of 3D matrix components solubilized by guanidine (followed by dialysis) (48) could not mimic any of the enhancing effects of 3D matrix on attachment, spreading, or proliferation. Conversely, not only does providing a collagenous three-dimensional matrix not suffice, but even a fibrillar matrix formed from purified fibronectin does not, implying that some molecular component in the 3D matrix besides fibronectin is needed (47).

The specific type of integrin used by cells for interactions with an extracellular matrix seems to be matrix-specific. In collagen gels, the predominant functional integrin is $\alpha_{2} \beta_{1}$ (50). In contrast, in each of the dramatic effects observed by 3D matrices on cell attachment, morphology, migration, and proliferation, the dominant integrin involved is the fibronectin receptor $\alpha_{5} \beta_{1}$ integrin (47). Another fibronectin receptor, the $\alpha_{V} \beta_{3}$ integrin, is also important for cell interactions with purified fibronectin itself (requiring antibody inhibition by both anti- $\alpha_{\mathrm{V}}$ and $\alpha_{5}$ integrins), yet $65-88 \%$ of the cellular re-

Figure 2. Comparison of fibroblast cell shapes and localization of components in 2-dimensional and 3-dimensional environments. Cells on 2D substrates tend to spread onto the substrate in a flattened morphology (left panel), whereas cells attaching to 3D matrices rapidly assume an elongated morphology (right panel) that tends to mimic shapes of fibroblastic and mesenchymal cells in vivo. The $\alpha_{5}$ integrin (red) localizes to focal and fibrillar adhesions in cells on $2 \mathrm{D}$ substrates coated with fibronectin (green), whereas it is organized into thin, elongated 3D-matrix adhesions in the 3D matrix containing a complex fibronectin-containing network of fibrils. sponses of human fibroblasts to 3D matrices can be suppressed by antibody against $\alpha_{5}$ while only $27-36 \%$ inhibition is observed by the same antibody for fibroblasts on 2D fibronectin. This intriguing finding identifies a striking dominance or preference for this integrin when cells interact with 3D matrix it suggests that there may be either a hyperactivation of function of the $\alpha_{5} \beta_{1}$ integrin, a suppression of functions of other integrins, or some combination of these novel actions in an intriguing system of integrin crosstalk.

The adhesions formed by fibroblastic, mesenchymal, and neural crest cells to 3D matrices are distinct from both the focal adhesions and the fibrillar adhesions traditionally described and studied in cell culture $(7,16,47,51)$ (Figure 2). These novel "3Dmatrix adhesions" contain many of the same plaque proteins as are found in focal adhesions, such as paxillin, vinculin, and focal adhesion kinase (FAK). However, they lack the $\alpha_{\mathrm{V}} \beta_{3}$ integrin, and they are instead based on the $\alpha_{5} \beta_{1}$ integrin (Table 1).

Most intriguingly, unlike the very wellstudied tyrosine-phosphorylated forms of FAK in focal adhesions, the FAK in 3Dmatrix adhesions is poorly phosphorylated
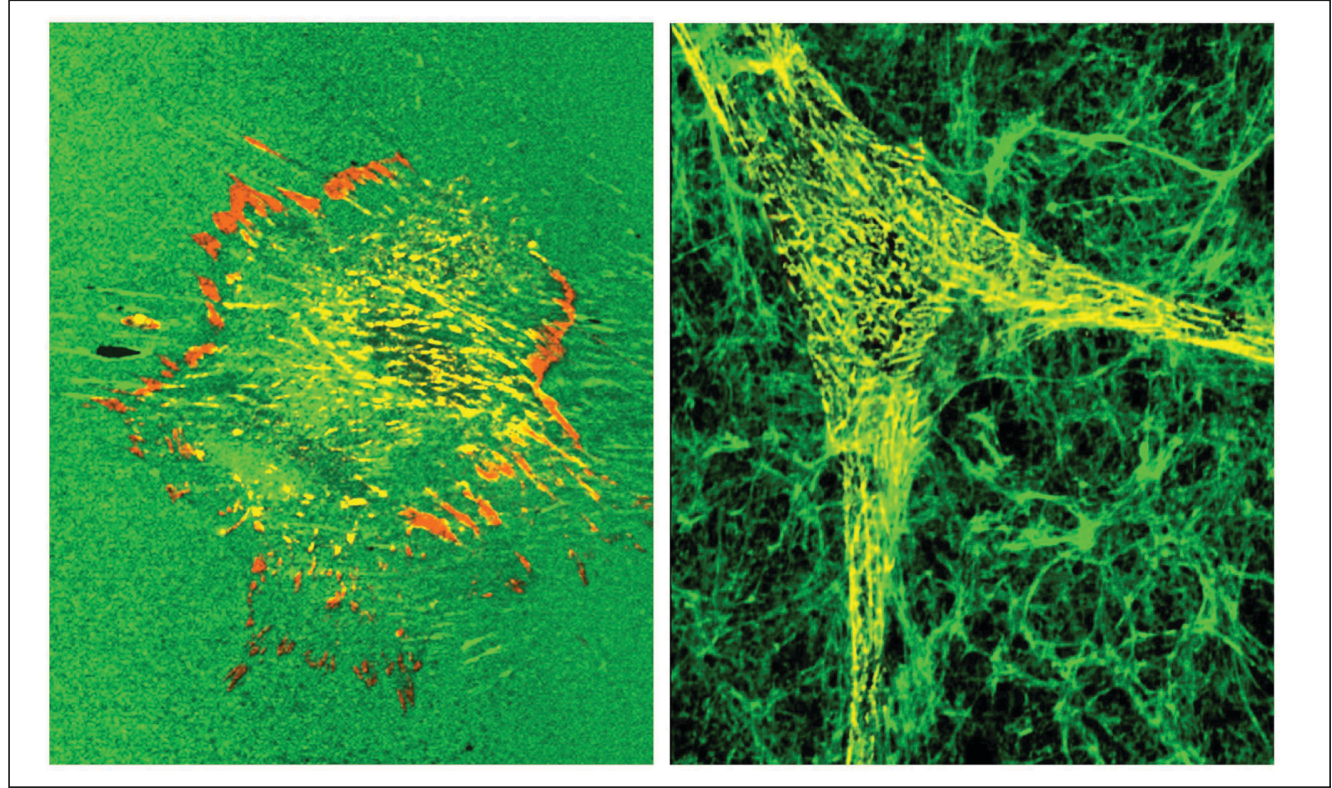
at its major tyrosine 397 phosphorylation site. This discrepancy in signaling in 2D versus $3 \mathrm{D}$ contexts is specific in that paxillin is equally phosphorylated at tyrosine 31 in both 3D-matrix adhesions and focal adhesions. Moreover, the extent of mitogen-activated protein kinase (extracellular signalregulated kinase, ERK) phosphorylation is moderately elevated (47), which may help contribute to the enhanced rate of proliferation in 3D matrix. Differences in signaling processes have also been reported in cells suspended in three-dimensional collagen gels when compared to 2D cultures (52-54), or under different loading conditions for collagen gel contraction measurements (40-42). The important conclusion from these reports is that studies of signaling in regular cell culture may provide misleading results: cells may have different signaling responses when they exist in three-dimensional settings that mimic in vivo conditions more closely. Future studies of cell interactions with extracellular matrix and signal transduction should therefore ideally be designed with these principles in mind.

\section{Cellular responses to extracellular matrices - the importance of matrix rigidity}

A previous analysis of the role of matrix pliability/rigidity revealed that the ability of cells to physically move and rearrange fibronectin was important in determining the nature of the cell adhesions that form on a 2D substrate. If fibronectin is cross-linked to a substrate, rather than being adsorbed and able to be remodeled, it results in exaggerated focal adhesions and trapping of the $\alpha_{5}$ integrin in these adhesions rather than translocating away to form fibrillar adhesions (55). Not surprisingly, fibronectin matrix assembly was blocked in the absence of these latter adhesions involved in generating fibronectin fibrils $(30,55)$. This response to immobilized fibronectin may be due to the development of increased tension within cells against the fixed fibronectin substrate. Effects of local tension can be mimicked by experimentally applying external physical tension near focal adhesions, which causes enlargement of these structures; there is a dynamic relationship between the forces on adhesions and their size and function $(7,56,57)$.

If 3D matrices are stiffened and immobilized by chemical cross-linking, a similar enhancement of focal adhesion-like structures occurs. Normal 3D-matrix adhesions are lost, and $\alpha_{5}$ integrins remain confined to focal adhesions (47). Thus, one can view the pliability or capacity for rearrangement of matrix components as being another important element of cellular responses to the extracellular matrix, along with its biochemical composition and three-dimensionality (Figure 3).

Table 1. Molecular compositions of three types of cell adhesions.

\begin{tabular}{|l|c|c|c|}
\hline Molecule & $\begin{array}{c}\text { Focal } \\
\text { adhesion } \\
\text { (mature) }\end{array}$ & $\begin{array}{c}\text { Fibrillar } \\
\text { adhesion }\end{array}$ & $\begin{array}{c}\text { 3D-matrix } \\
\text { adhesion }\end{array}$ \\
\hline$\alpha_{5}$ integrin & $\mathbf{-}$ & + & + \\
\hline$\beta_{1}$ integrin & $\mathbf{+}$ & $\mathbf{+}$ & $\mathbf{+}$ \\
\hline$\beta_{3}$ integrin & $\mathbf{+}$ & - & - \\
\hline paxillin & $\mathbf{+}$ & - & $\mathbf{+}$ \\
\hline tensin & $\mathbf{+}$ & $\mathbf{+}$ & $\mathbf{+}$ \\
\hline talin & $\mathbf{+}$ & $\mathbf{+}$ & $\mathbf{+}$ \\
\hline vinculin & $\mathbf{+}$ & - & $\mathbf{+}$ \\
\hline $\begin{array}{l}\text { phospho- } \\
\text { tyrosine }\end{array}$ & $\mathbf{+}$ & - & $\mathbf{+}$ \\
\hline FAK & $\mathbf{+}$ & - & $\mathbf{+}$ \\
\hline $\begin{array}{l}\text { phospho- } \\
\text { FAK }\left[\mathrm{Y}^{397}\right]\end{array}$ & $\mathbf{+}$ & - & - \\
\hline
\end{tabular}

There are similarities and differences between the molecules found in focal, fibrillar, and 3D-matrix adhesions as indicated in this table showing selected components of these cell-matrix adhesions. Components indicated in black are characteristically present in mature focal adhesions. If that component differs in fibrillar or 3D-matrix adhesions compared to focal adhesions, it is indicated in red. For example, phosphorylation at tyrosine 397 of focal adhesion kinase (FAK) is deficient in both fibrillar and 3D-matrix adhesions. P indicates that this integrin is localized only at the periphery of mature focal adhesions. 
Figure 3. Cells respond to distinct physical and biochemical characteristics of the extracellular matrix. Although it is well known that cells respond in differing fashion to distinct matrix molecules (i.e., composition of the matrix), they also respond to differences in pliability of the matrix, to tension forces, and to the spatial nature of the matrix (3D versus 2D). These responses result in a variety of adhesion structures formed in response to diverse environmental cues.

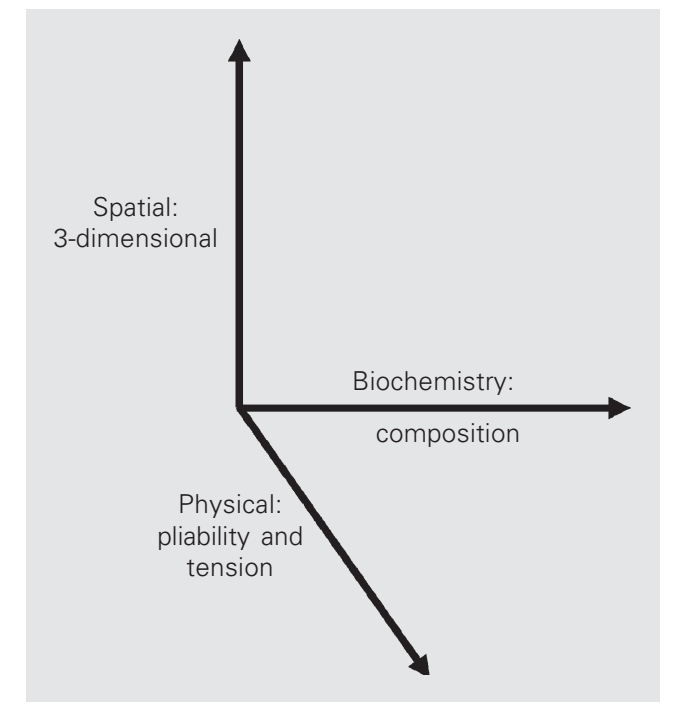

Figure 4. Summary of cellular responses to the extracellular matrix. The responses of cells to extracellular matrix differ depending on its organization and the type of cell adhesion. Focal adhesions are localized sites of firm anchorage to a relatively rigid substrate molecule such as vitronectin, in which integrins such as $\alpha v \beta_{3}$ organize intracellular complexes of adhesion complex components that include focal adhesion kinase (FAK), paxillin, and tensin, as well as classical signaling molecules such as Src and ERK. In addition, novel components such as kinectin (58) are being discovered; the number of components is already greater than thirty, and more are expected. Fibrillar adhesions extend towards the cell center from the edges of focal adhesions. They consist of the

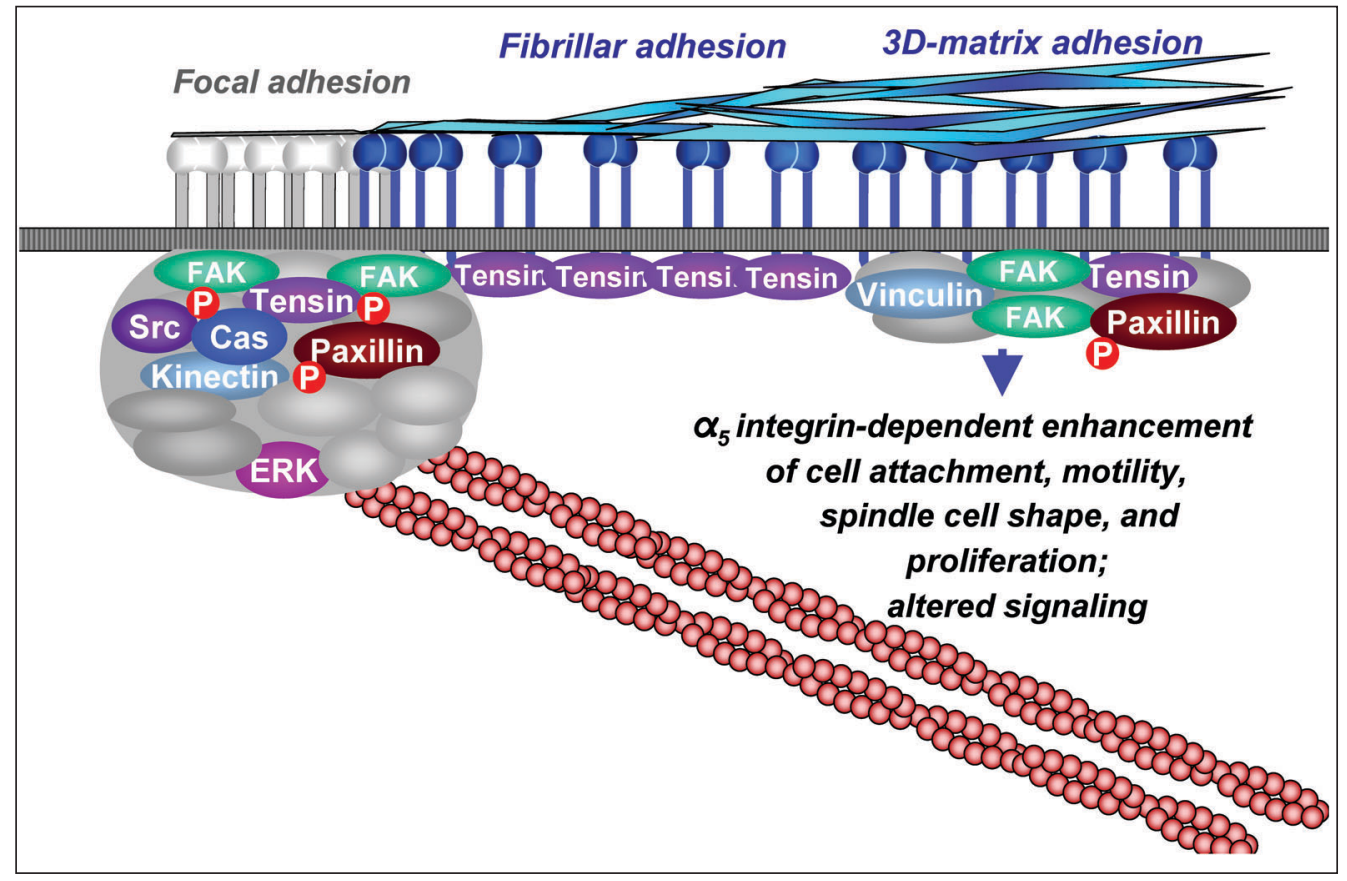
$\alpha_{5} \beta_{1}$ fibronectin receptor in as-

sociation with extracellular fibronectin fibrils and with intracellular tensin, talin, and actin microfilaments within a pliable extracellular substrate that consists of more than one matrix component. They tend to have low levels of tyrosine phosphorylation. Finally, when cells interact with 3D extracellular matrix, they form 3D-matrix adhesions that contain various adhesion complex proteins such as paxillin, vinculin, FAK, and tensin. Even though tyrosine 31 of paxillin is phosphorylated to levels similar to those found in cells forming extensive focal adhesions on 2D substrates, the phosphorylation of tyrosine 397 of FAK is strikingly decreased, indicating differential alterations in signaling. Cell interactions with fibronectin-rich 3D matrices are characterized by enhanced rates of cell attachment, acquisition of an elongated, spindle cell shape, cell proliferation, and motility. These interactions are mediated primarily by the $\alpha_{5} \beta_{1}$ integrin and depend on matrix pliability. Besides the difference in FAK signal transduction, there are significant effects on activation of ERK, a central regulatory mitogen-activated protein kinase. 


\section{Concluding remarks}

Integrin-mediated cell interactions with extracellular matrix now appear to be considerably more complex and sophisticated than originally envisioned. The existence of different types of adhesions in the same cell, as well as differences in the molecular composition of adhesions, signaling, and biological functions in two-dimensional versus three-dimensional environments (Figure 4) provides both enlightenment and a concern. It seems obvious in retrospect that different functions of cell-matrix interactions should require different types of adhesions (i.e., focal adhesions for the strongest level of adhesion and fibrillar adhesions for permitting dynamic assembly of matrix fibrils). On the other hand, focal adhesions can them- selves translocate under certain conditions (59), and the existence of multiple types of adhesions forces us to re-think concepts about the actual sites from which integrin-mediated signaling may originate. A concern, which is probably healthy, is that studies of different cell types and different model matrices, whether $2 \mathrm{D}$ or $3 \mathrm{D}$, are likely to give different answers to experimental questions as the cells utilize different types of adhesion structures. However, the comforting aspect of this complexity is that it is now clear that cells have many ways in which to accomplish the subtle variations and major changes in function that they require for maintaining normal physiological function in the intact organism and in responding to injury and other challenges.

\section{References}

1. Giancotti FG \& Ruoslahti E (1999). Integrin signaling. Science, 285: 1028-1032.

2. Humphries MJ (2000). Integrin structure. Biochemical Society Transactions, 28: 311-339.

3. Hynes RO (2002). Integrins: Bidirectional, allosteric signaling machines. Cell, 110: 673-687.

4. Miranti CK \& Brugge JS (2002). Sensing the environment: A historical perspective on integrin signal transduction. Nature Cell Biology, 4: E83-E90.

5. Yamada KM \& Danen EHJ (2000). Integrin signaling. In: Gutkind JS (Editor), Signaling Networks and Cell Cycle Control. Humana Press, Totowa, NJ, USA, 1-25.

6. Schwartz MA \& Ginsberg MH (2002). Networks and crosstalk: Integrin signalling spreads. Nature Cell Biology, 4: E65-E68.

7. Geiger B, Bershadsky A, Pankov R \& Yamada KM (2001). Transmembrane cross-talk between the extracellular matrix and the cytoskeleton. Nature Reviews. Molecular Cell Biology, 2: 793-805.

8. Danen EH \& Yamada KM (2001). Fibronectin, integrins, and growth control. Journal of Cellular Physiology, 189: 1-13.

9. Damsky CH \& llic D (2002). Integrin signaling: It's where the action is. Current Opinion in Cell Biology, 14: 594-602.

10. Aplin AE, Howe AK \& Juliano RL (1999). Cell adhesion molecules, signal transduction and cell growth. Current Opinion in Cell Biology, 11: 737-744.

11. Stupack DG \& Cheresh DA (2002). Get a ligand, get a life: Integrins, signaling and cell survival. Journal of Cell Science, 115: 3729-3738.

12. Springer TA (2002). Predicted and experimental structures of integrins and beta-propellers. Current Opinion in Structural Biology, 12: 802-813.

13. Arnaout $M$, Goodman S \& Xiong J (2002). Coming to grips with integrin binding to ligands. Current Opinion in Cell Biology, 14: 641-
651.

14. Brown E (2002). Integrin-associated proteins. Current Opinion in Cell Biology, 14: 603-607.

15. Howe AK, Aplin AE \& Juliano RL (2002). Anchorage-dependent ERK signaling - mechanisms and consequences. Current Opinion in $\mathrm{Ge}-$ netics and Development, 12: 30-35.

16. Sastry SK \& Burridge K (2000). Focal adhesions: A nexus for intracellular signaling and cytoskeletal dynamics. Experimental Cell Research, 261: 25-36.

17. Shimaoka M, Takagi J \& Springer TA (2002). Conformational regulation of integrin structure and function. Annual Review of Biophysics and Biomolecular Structure, 31: 485-516.

18. Yamada KM \& Even-Ram S (2002). Integrin regulation of growth factor receptors. Nature Cell Biology, 4: E75-E76.

19. Takagi J \& Springer TA (2002). Integrin activation and structural rearrangement. Immunological Reviews, 186: 141-163.

20. McDonald JA, Kelley DG \& Broekelmann TJ (1982). Role of fibronectin in collagen deposition: Fab' to the gelatin-binding domain of fibronectin inhibits both fibronectin and collagen organization in fibroblast extracellular matrix. Journal of Cell Biology, 92: 485-492.

21. Velling $T$, Risteli J, Wennerberg K, Mosher DF \& Johansson S (2002). Polymerization of type I and III collagens is dependent on fibronectin and enhanced by integrins alpha 11 beta 1 and alpha 2 beta 1. Journal of Biological Chemistry, 277: 37377-37381.

22. Sottile J \& Hocking DC (2002). Fibronectin polymerization regulates the composition and stability of extracellular matrix fibrils and cellmatrix adhesions. Molecular Biology of the Cell, 13: 3546-3559.

23. Schwarzbauer JE \& Sechler JL (1999). Fibronectin fibrillogenesis: A paradigm for extracellular matrix assembly. Current Opinion in Cell Biology, 11: 622-627.

24. Vogel V, Thomas WE, Craig DW, Krammer A \& Baneyx G (2001). 
Structural insights into the mechanical regulation of molecular recognition sites. Trends in Biotechnology, 19: 416-423.

25. Hocking DC, Sottile J \& McKeown-Longo PJ (1998). Activation of distinct alpha5beta1-mediated signaling pathways by fibronectin's cell adhesion and matrix assembly domains. Journal of Cell Biology, 141: 241-253.

26. Zhong C, Chrzanowska-Wodnicka M, Brown J, Shaub A, Belkin AM \& Burridge K (1998). Rho-mediated contractility exposes a cryptic site in fibronectin and induces fibronectin matrix assembly. Journal of Cell Biology, 141: 539-551.

27. Pankov R \& Yamada KM (2002). Fibronectin at a glance. Journal of Cell Science, 115: 3861-3863.

28. Ohashi T, Kiehart DP \& Erickson HP (2002). Dual labeling of the fibronectin matrix and actin cytoskeleton with green fluorescent protein variants. Journal of Cell Science, 115: 1221-1229.

29. Ohashi T, Kiehart DP \& Erickson HP (1999). Dynamics and elasticity of the fibronectin matrix in living cell culture visualized by fibronectin-green fluorescent protein. Proceedings of the National Academy of Sciences, USA, 96: 2153-2158.

30. Pankov R, Cukierman E, Katz BZ, Matsumoto K, Lin DC, Lin S, Hahn C \& Yamada KM (2000). Integrin dynamics and matrix assembly: Tensin-dependent translocation of $\alpha_{5} \beta_{1}$ integrins promotes early fibronectin fibrillogenesis. Journal of Cell Biology, 148: 1075-1090.

31. Zamir E, Katz M, Posen Y et al. (2000). Dynamics and segregation of cell-matrix adhesions in cultured fibroblasts. Nature Cell Biology, 2: 191-196.

32. Hay ED (1991). Cell Biology of Extracellular Matrix. 2nd edn. Vol. 1. Plenum Press, New York.

33. Friedl P \& Brocker EB (2000). The biology of cell locomotion within three-dimensional extracellular matrix. Cellular and Molecular Life Sciences, 57: 41-64.

34. Friedl P \& Brocker EB (2000). T cell migration in three-dimensional extracellular matrix: Guidance by polarity and sensations. Developmental Immunology, 7: 249-266.

35. Bissell MJ \& Radisky D (2001). Putting tumours in context. Nature Reviews. Cancer, 1: 46-54.

36. Cukierman E, Pankov R \& Yamada KM (2002). Cell interactions with three-dimensional matrices. Current Opinion in Cell Biology, 14: 633-639

37. Walpita D \& Hay E (2002). Studying actin-dependent processes in tissue culture. Nature Reviews. Molecular Cell Biology, 3: 137-141.

38. Bissell MJ, Radisky DC, Rizki A, Weaver VM \& Petersen OW (2002). The organizing principle: Microenvironmental influences in the normal and malignant breast. Differentiation, 70: 537-546.

39. Hagios C, Lochter A \& Bissell MJ (1998). Tissue architecture: The ultimate regulator of epithelial function? Philosophical Transactions of the Royal Society of London. Series B: Biological Sciences, 353: 857-870.

40. Halliday NL \& Tomasek JJ (1995). Mechanical properties of the extracellular matrix influence fibronectin fibril assembly in vitro. Experimental Cell Research, 217: 109-117.

41. Grinnell F (2000). Fibroblast-collagen-matrix contraction: Growthfactor signalling and mechanical loading. Trends in Cell Biology, 10: 362-365

42. Grinnell F \& Ho CH (2002). Transforming growth factor beta stimulates fibroblast-collagen matrix contraction by different mechanisms in mechanically loaded and unloaded matrices. Experimental Cell Research, 273: 248-255

43. Brown RA, Sethi KK, Gwanmesia I, Raemdonck D, Eastwood M \& Mudera $V$ (2002). Enhanced fibroblast contraction of 3D collagen lattices and integrin expression by TGF-beta1 and -beta3: Mechanoregula- tory growth factors? Experimental Cell Research, 274: 310-322.

44. Aggeler J, Park CS \& Bissell MJ (1988). Regulation of milk protein and basement membrane gene expression: The influence of the extracellular matrix. Journal of Dairy Science, 71: 2830-2842.

45. Weaver VM, Lelievre S, Lakins JN, Chrenek MA, Jones JC, Giancotti F, Werb Z \& Bissell MJ (2002). Beta4 integrin-dependent formation of polarized three-dimensional architecture confers resistance to apoptosis in normal and malignant mammary epithelium. Cancer Cell, 2: 205-216.

46. Debnath J, Mills KR, Collins NL, Reginato MJ, Muthuswamy SK \& Brugge JS (2002). The role of apoptosis in creating and maintaining luminal space within normal and oncogene-expressing mammary acini. Cell, 111: 29-40.

47. Cukierman E, Pankov R, Stevens DR \& Yamada KM (2001). Taking cell-matrix adhesions to the third dimension. Science, 294: 17081712

48. Cukierman E (2002). Preparation of extracellular matrices produced by cultured fibroblasts. In: Bonifacino JS, Dasso M, LippincottSchwartz J, Harford JB \& Yamada KM (Editors), Current Protocols in Cell Biology. John Wiley \& Sons, New York, 10.19.11-10.19.14.

49. Elsdale T \& Bard J (1972). Collagen substrata for studies on cell behavior. Journal of Cell Biology, 54: 626-637.

50. Maaser K, Wolf K, Klein CE, Niggemann B, Zanker KS, Brocker EB \& Friedl P (1999). Functional hierarchy of simultaneously expressed adhesion receptors: Integrin alpha2beta1 but not CD44 mediates MV3 melanoma cell migration and matrix reorganization within three-dimensional hyaluronan-containing collagen matrices. Molecular Biology of the Cell, 10: 3067-3079.

51. Geiger B \& Bershadsky A (2002). Exploring the neighborhood: Adhesion-coupled cell mechanosensors. Cell, 110: 139-142.

52. Ishii I, Tomizawa A, Kawachi $\mathrm{H}$ et al. (2001). Histological and functional analysis of vascular smooth muscle cells in a novel culture system with honeycomb-like structure. Atherosclerosis, 158: 377384.

53. Ravanti L, Heino J, Lopez-Otin C \& Kahari V-M (1999). Induction of collagenase-3 (MMP-13) expression in human skin fibroblasts by three-dimensional collagen is mediated by p38 mitogen-activated protein kinase. Journal of Biological Chemistry, 274: 2446-2455.

54. Vaalamo M, Mattila L, Johansson N, Kariniemi AL, KarjalainenLindsberg ML, Kahari VM \& Saarialho-Kere U (1997). Distinct populations of stromal cells express collagenase-3 (MMP-13) and collagenase-1 (MMP-1) in chronic ulcers but not in normally healing wounds. Journal of Investigative Dermatology, 109: 96-101.

55. Katz BZ, Zamir E, Bershadsky A, Kam Z, Yamada KM \& Geiger B (2000). Physical state of the extracellular matrix regulates the structure and molecular composition of cell-matrix adhesions. Molecular Biology of the Cell, 11: 1047-1060.

56. Riveline D, Zamir E, Balaban NQ, Schwarz US, Ishizaki T, Narumiya S, Kam Z, Geiger B \& Bershadsky AD (2001). Focal contacts as mechanosensors: Externally applied local mechanical force induces growth of focal contacts by an mDia1-dependent and ROCK-independent mechanism. Journal of Cell Biology, 153: 1175-1186.

57. Balaban NO, Schwarz US, Riveline D et al. (2001). Force and focal adhesion assembly: A close relationship studied using elastic micropatterned substrates. Nature Cell Biology, 3: 466-472.

58. Tran H, Pankov R, Tran SD, Hampton B, Burgess WH \& Yamada KM (2002). Integrin clustering induces kinectin accumulation. Journal of Cell Science, 115: 2031-2040.

59. Smilenov LB, Mikhailov A, Pelham RJ, Marcantonio EE \& Gundersen GG (1999). Focal adhesion motility revealed in stationary fibroblasts. Science, 286: 1172-1174 